\title{
Mutually Exclusive Expression of COL11A1 by CAFs and Tumour Cells in a Large panCancer and a Salivary Gland Carcinoma Cohort
}

\author{
Christoph Arolt ${ }^{1}$ (D) Franziska Hoffmann ${ }^{2}$ - Lisa Nachtsheim ${ }^{3} \cdot$ Philipp Wolber $^{3} \cdot$ Orlando Guntinas-Lichius $^{4}$. \\ Reinhard Buettner ${ }^{1} \cdot$ Ferdinand von Eggeling $^{4,5}$ • Alexander Quaas ${ }^{1}$. Jens Peter Klußmann ${ }^{3,6}$
}

Received: 14 June 2021 / Accepted: 26 July 2021 / Published online: 10 August 2021

(c) The Author(s) 2021, corrected publication 2021

\begin{abstract}
Procollagen 11A1 (COL11Al) is a central component of the extracellular matrix in many carcinomas, which is considered to be mainly produced by cancer associated fibroblasts (CAFs). As COL11Al expression correlates with adverse prognosis and is implicated in chemoresistance, it is a promising putative target. For the first time, we used RNA in-situ hybridization to systematically identify the cells that produce COL11A1 in the ten most prevalent carcinoma types, lymphomas $(\mathrm{n}=275)$ and corresponding normal tissue $(\mathrm{n}=55$; panCancer cohort). Moreover, as most salivary gland carcinomas (SGC) display distinct stromal architectures, we also analysed 110 SGC. The corresponding protein formation of COL11A1 was determined by MALDI-TOF-MS-Imaging. We report that colon, breast and salivary duct carcinomas are highly infiltrated by COL11A1 positive CAFs ( $\mathrm{CAFs}_{\text {COL11AI }}$ ) and might thus be promising candidates for antidesmoplastic or COL11A1targeted therapies. The amount of $\mathrm{CAFs}_{\mathrm{COL11Al}}$ correlated significantly with tumour grade, tumour stage and nodal spread in the panCancer cohort. Significant associations between $\mathrm{CAFs}_{\mathrm{COL11Al}}$ and vascular invasion, perineural spread and nodal spread were observed in the SGC cohort. Also, we discovered that tumour cells of intercalated duct derived SGC and CAFs produce COL11Al in a mutually exclusive manner. Our findings represent a novel mode of extracellular matrix production in carcinomas and could be highly relevant in the future. Our findings elucidate the mode of COL11Al expression in very different carcinoma types and may aid to categorise tumours in the setting of possible future COL11A1-related therapies.
\end{abstract}

Keywords COL11A1 · CAFs · Salivary gland carcinoma $\cdot$ Tumour microenvironment $\cdot$ Extracellular matrix $\cdot$ RNA-ISH

Alexander Quaas and Jens Peter Klußmann have contributed equally to this work.

Christoph Arolt

Christoph.arolt@uk-koeln.de

Franziska Hoffmann

Franziska.Hoffmann@med.uni-jena.de

Lisa Nachtsheim

lisa.nachtsheim@uk-koeln.de

Philipp Wolber

philipp.wolber@uk-koeln.de

Orlando Guntinas-Lichius

Orlando.Guntinas@med.uni-jena.de

Reinhard Buettner

reinhard.buettner@uk-koeln.de

Ferdinand von Eggeling

Ferdinand.von_Eggeling@med.uni-jena.de

Alexander Quaas

alexander.quaas@uk-koeln.de

Jens Peter Klußmann

jens.klussmann@uk-koeln.de
1 Medical Faculty, Institute of Pathology, University of Cologne, Kerpener Straße 62, 50937 Cologne, Germany

2 Department of Otorhinolaryngology, MALDI Imaging and Innovative Biophotonics, Jena University Hospital, 07747 Jena, Germany

3 Department of Otorhinolaryngology, Head and Neck Surgery, Medical Faculty, University of Cologne, 50937 Cologne, Germany

4 Department of Otorhinolaryngology, Head and Neck Surgery, Jena University Hospital, 07747 Jena, Germany

5 MALDI Imaging, Core Unit Proteome Analysis, DFG Core Unit Jena Biophotonic and Imaging, Laboratory (JBIL), Jena University Hospital, 07747 Jena, Germany

6 Medical Faculty, Centre for Molecular Medicine Cologne (CMMC), University of Cologne, 50937 Cologne, Germany 


\begin{tabular}{|c|c|}
\hline \multicolumn{2}{|c|}{ Abbreviations } \\
\hline COL11A1 & Procollagen 11A1 \\
\hline CAFs & Cancer associated fibroblasts \\
\hline SGC & Salivary gland carcinomas \\
\hline $\mathrm{CAFs}_{\text {COLIIAI }}$ & COL11A1 positive CAFs \\
\hline TME & Tumour microenvironment \\
\hline ECM & Extracellular matrix \\
\hline MC & Breast carcinoma \\
\hline CRC & Colorectal carcinoma \\
\hline $\mathrm{OC}$ & Ovarian carcinoma \\
\hline PDAC & Pancreatic ductal adenocarcinoma \\
\hline $\mathrm{AdCy}$ & Adenoid cystic carcinoma \\
\hline MuEp & Mucoepidermoid carcinoma \\
\hline $\mathrm{SaDu}$ & Salivary duct carcinoma \\
\hline TMA & Tissue microarray \\
\hline FFPE & Formalin-fixed paraffin-embedded \\
\hline RNA-ISH & RNA in-situ hybridization \\
\hline IHC & Immunohistochemistry \\
\hline MSI & MALDI-TOF-MS-Imaging \\
\hline $\mathrm{TC}_{\text {COL11A1 }}$ & Tumour cells with COL11A1 staining \\
\hline ER & Oestrogen receptor \\
\hline Acin & Acinic cell carcinoma \\
\hline $\mathrm{Sec}$ & Secretory carcinoma \\
\hline EpMy & Epithelial-myoepithelial carcinoma \\
\hline ANOS & Adenocarcinoma not otherwise specified \\
\hline Bas & Basal cell adenocarcinoma \\
\hline MyEp & Myoepithelial carcinoma \\
\hline FAO & Fatty acid oxidase \\
\hline
\end{tabular}

\section{Introduction}

As the efficacy of mutation-specific therapies is limited by resistance mechanisms, more recently, the interest of cancer research has expanded towards the non-neoplastic tumour microenvironment (TME). It provides tumour promoting growth factors, an aberrant neo-vasculature and an immune milieu that supports the growth of neoplastic cells [1-4]. More than $50 \%$ of the tumour surface can be attributed to the desmoplastic stroma, a highly specialised extracellular matrix (ECM) [5] which is considered to be secreted by cancer associated fibroblasts (CAFs) $[6,7]$. Several agents that target either CAFs or the ECM are currently being trialed [8].

Procollagen 11A1 (COL11A1), the $\alpha 1$ chain of collagen $\mathrm{XI}$, has been found to be consistently upregulated in the ECM of different carcinoma types [9]. Also, an overexpression of COL11A1 has been associated with an adverse outcome in a variety of primaries including breast (MC) [10], colorectum (CRC) [9], ovary (OC) [9, 11], lung [12], bladder [13], kidney [14] and pancreas (PDAC) [15]. GarcíaPravia et al. and Jia et al. revealed that in PDAC and CRC, this overexpression of COL11Al can be traced back to intratumoral CAFs $[9,16]$. Physiologically, COL11A1 is expressed in cartilaginous tissues and mesenchymal stem cells while it is nearly undetectable in other normal tissues including resident fibroblasts and most benign sclerotic conditions [9, 17-20]. This relative specificity is an advantage over other fibroblast markers such as aSMA, PDFGR 3 or FAP and could make COL11A1 a more reliable indicator for a CAF phenotype $[20,21]$. Also, the expression of COL11A1 has been associated with upregulation pathways that are typically active in CAFs [20]. Also more recently, Wu et al. and Nallantighal et al. [22, 23] have mechanistically demonstrated that COL11A1 expression can lead to chemoresistance by the induction of apoptosis inhibitor proteins [11] and fatty acid oxidase [22]. Thus, COL11Al is a promising candidate for targeted therapy.

Salivary gland carcinomas (SGC) are a group of rare and heterogenous tumour entities. Most salivary gland carcinoma subtypes exhibit pathognomonic growth patterns and sometimes entity-defining gene translocations [24]. This group of carcinomas makes up the vast majority of SGC as it comprises the most prevalent subtypes such as adenoid cystic carcinomas (AdCy) and mucoepidermoid carcinomas (MuEp). Unfortunately, most entity-specific gene translocations cannot yet be therapeutically targeted. The lack of options for efficient systemic therapy has prompted the exploration of the TME of SGC. While the presence of several immune checkpoint molecules has been recently reported [25-27], the extracellular matrix or the presence of CAFs in the TME of SGC has not yet been systematically addressed.

Recently, we have discovered that in SGC, COL11Al is not only expressed by CAFs but also by AdCy tumour cells [28]. As COL11A1 is a promising therapeutic target due to its involvement in chemoresistance, in the present study, we used RNA in-situ staining to determine the frequency of COL11A1 positive CAFs (CAFs COL11AI $_{\text {) }}$ and tumour cells in a large cohort of different SGC and the ten most prevalent carcinoma primaries on tissue microarrays (TMA). We reveal that SGC arising from the excretory duct display higher frequencies of $\mathrm{CAFs}_{\mathrm{COL11AI}}$ than any other primary we analysed. Of note, COL11A1 expression by tumour cells was nearly exclusive to SGC that are derived from the intercalated duct or the acini. Our results indicate that therapeutic targeting of COL11A1 might have a particularly high potential in SGC.

\section{Materials and Methods}

\section{Recruitment of Patients and TMA Preparation}

For the SGC cohort, all formalin-fixed paraffin-embedded (FFPE) SGC specimen, which were resected at the 
Department of Oto-Rhino-Laryngology, Head and Neck Surgery of the University of Cologne between 1998 and 2018 were retrieved from the archives of the Institute of Pathology, University Hospital of Cologne $(n=110)$. All cases were revised in detail by two pathologists (CA, AQ). Immunohistochemical staining for CK7, p63, NOR-1, S100, androgen receptor and HER2 as well as FISH break-apart analysis for MYB, MYBL1, MAML2 and ETV6 genes were employed in case the original diagnosis would not be unequivocal. For the panCancer cohort, 25 cases of each tumour type as well as five tissue blocks with the respective normal tissue were retrieved from the archives. These cases comprised the ten most prevalent carcinoma types according to the US National Cancer Institute [29] as well as the different lymphomas (Table S1). Cases were selected in order to mirror the actual relative prevalence of each grade and tumour subtype (e.g., growth pattern, ER positivity in case of breast carcinomas) while also including rare forms. If available, basic clinicopathological data as sex, age and TNM classification were recorded. Before TMA preparation, it was ensured that sufficient residual tumour material for possible complementary diagnostic tests would be available afterwards. TMAs were prepared as described before [25]. Briefly, four tissue cylinders in case of the SGC cohort and two tissue cylinders in case of the panCancer cohort were punched out from FFPE block and transferred to an empty paraffin block. All procedures were in accordance with the ethical standards of the University of Cologne and the Helsinki Declaration from 1975 and its revision in 1983. Patients gave their written informed consent to participate in this study.

\section{RNA In-Situ Hybridization (RNA-ISH) and Immunohistochemistry (IHC)}

The RNAscope assays were performed according to the manufacturer's instruction, as previously reported [30]. Briefly, $5 \mu \mathrm{m}$ sections were cut from FFPE blocks, pretreated (30 min for pre-treatment 2 and 3), digested and hybridised at $40{ }^{\circ} \mathrm{C}$ with mRNA probes specific for human COL11A1 (each ready to use, Advanced Cell Diagnostics, Bio-Techne, Minneapolis, MN, USA) using a Ventana Discovery system (Roche, Switzerland). Subsequently, the slides were counterstained for $10 \mathrm{~s}$ in haematoxylin. Immunohistochemical staining of CD8 $+\mathrm{T}$ cells and p53 mutation status was carried out before for this cohort. Tumours were termed "inflamed" if the amount of $\mathrm{CD} 8+\mathrm{T}$ cells exceeded $>100$ per core [25].

\section{Semiquantitative Scoring of CAFs COL11A1 $_{1}$}

$\mathrm{CAFs}_{\text {COL11AI }}$ in the tumour tissue were morphologically identified. The percentage of COL11A1-positive stromal surface as indicator for $\mathrm{CAFs}_{\mathrm{COLIIAl}}$ was recorded by two pathologists (C.A. and A.Q.) as follows: $0:<1 \% ; 1: 1-20 \%$; 2: $21-50 \% ; 3:>50 \% ; 4:>50 \%$ and high staining intensity due to frequently merged RNA-ISH signals. As two (panCancer cohort) and four (SGC cohort) TMA-cores of $1 \mathrm{~mm}$ diameter were scored per case, the upper median was chosen as resulting score for further statistical analysis. The percentage of $\mathrm{TC}_{\text {COLIIAl }}$ was noted for each spot and the mean percentage was calculated. For binary analyses, cases with $\mathrm{CAFs}_{\text {COL11Al }}$ score $\geq 1$ or $\geq 1 \% \mathrm{TC}_{\text {COL11Al }}$ were designated stroma-positive or tumour cell-positive, respectively.

\section{Detection of COL11A1 Protein by MALDI-TOF- MS-Imaging (MSI)}

For the detection of the protein expression, TMAs with samples from 41 patients of the SGC cohort and from 100 patients of the panCancer cohort (breast, prostate, lung, colorectum $n=25$ each) were used. Sample preparation, MSI data acquisition as well as data and imaging analysis were performed as previously published [28]. We detected one COL11A1 peptide after tryptic cleavage [(R) GEKGEAGPPGAAGPPGAK $(\mathrm{G})$; $\mathrm{m} / \mathrm{z}$ value: 1545.82$]$. From this peptide, four adducts, $[\mathrm{M}+\mathrm{H}]+(1546.828 \mathrm{~m} / \mathrm{z})$, $[\mathrm{M}+\mathrm{NH} 4]+(1563.854 \mathrm{~m} / \mathrm{z}),[\mathrm{M}+\mathrm{Na}]+(1568.81 \mathrm{~m} / \mathrm{z})$ and $[\mathrm{M}+\mathrm{K}]+(1584.784 \mathrm{~m} / \mathrm{z})$ were recognised. As all adducts were distributed equally among the different tumour types, only the measurements for the $[\mathrm{M}+\mathrm{H}]+$ adduct were used for further comparisons.

\section{Statistical Analysis}

Statistical analysis was carried out with SPSS statistical software (IBM SPSS 25.0, Armonk, NY). Bar plots and dot plots were drawn with RStudio (R Foundation for Statistical Computing, Vienna, Austria.) and the R package ggplot2 [31]. Interdependencies between categorical variables were tested using Fisher's exact test or Pearson's Chi-square test depending of the group size. Correlations between ordinal variables were calculated with spearman's rank correlation coefficient. A Kruskal-Wallis-Test with p value correction was employed for the comparisons of COL11A1 protein expression between different tumour types. $\mathrm{P}$ values below 0.05 were considered significant.

\section{Results}

\section{The Highest Frequency of CAFs $\mathrm{COL11A1}_{11}$ can be observed in SGC, MC and Colon CRC}

The panCancer cohort $(n=275)$ comprised the ten most prevalent carcinoma types as well as lymphomas ( 25 cases 
each). Additionally, five samples of normal tissue of each respective organ were included $(n=55)$. We measured the infiltration by $\mathrm{CAFs}_{\text {COLIIAI }}$ using a semiquantitative score (Score $0-4$ ) that reflected the percentage of stromal surface stained by the COL11A1 RNA-ISH. Additionally, we assessed the percentage of tumour cells with COL11A1 staining $\left(\mathrm{TC}_{\text {COL11AI }}\right)$. CAFs $\mathrm{COLI1Al}_{\text {I }}$ were almost exclusively observed in tumour tissues with an overall positivity rate of $34.5 \%$ compared to $1.6 \%$ in normal tissue (one positive endometrium sample). We observed dramatic differences of CAFs $\mathrm{COLI1Al}_{\text {infiltration across different primary sites }}$ (Fig. 1 and Table S1). The highest frequencies of positive tumours were noted for CRC (79\%), MC (75\%), gastric (48\%) and esophageal carcinomas (44\%), while only $8 \%$ and $4 \%$ of lymphomas and prostate carcinomas were infiltrated by $\mathrm{CAFs}_{\mathrm{COL11Al}}$. Interestingly, CRC, MC and esophageal carcinomas exhibited very similar frequencies of highly positive cases (Score 3), reaching 29.2\%, 33.3\% and 28\%, respectively. Conversely, only $8 \%$ of all stomach carcinomas were assigned to this category. None of the cases from the panCancer cohort exhibited confluent stromal COL11A1 staining required for the maximum CAFs ${ }_{\text {COL11Al }}$ Score of 4 , which was observed in several SGC subgroups.
When all cases of the panCancer cohort were pooled (Table 1), the $\mathrm{CAFs}_{\mathrm{COL11Al}}$ score strongly correlated with tumour grade $(\mathrm{p}=0.001)$ and tumour stage $(\mathrm{p}<0.001)$. To a lesser extent, but still significantly, $\mathrm{CAFs}_{\mathrm{COL11Al}}$ score also correlated with nodal spread $(\mathrm{p}=0.048)$. Moreover, a trend for a higher rate of lymphatic invasion and higher age and was observed for tumours with infiltration by $\mathrm{CAFs}_{\text {COL11AI }}$ ( $p$ values: 0.067 and 0.081 , respectively). The trend for a higher percentage of CAFs ${ }_{\text {COLIIAl }}$ infiltrated carcinomas among females $(p=0.078)$ resulted from the high percentage of MCs.

$\mathrm{MC}$ and CRC were infiltrated by $\mathrm{CAFs}_{\text {COLIIAI }}$ in over $50 \%$ of the cases and were consecutively studied in more detail. For MC (Table S2), a significant positive correlation with stromal CAFs COL11Al $_{\text {score was observed for }}$ tumour grade and Ki67 index $(0.478, \mathrm{p}=0.018$ and 0.656 , $\mathrm{p}=0.002$, respectively). Also, the presence of $\mathrm{CAFs}_{\text {COL11AI }}$ was associated with negativity for oestrogen receptor (ER), as $100 \%$ of ER- and only $54.5 \%$ of ER + MC were infiltrated by $\mathrm{CAFs}_{\text {COL11Al }}(\mathrm{p}=0.011)$. In this subgroup analysis, no significant dependency between $\mathrm{CAFs}_{\mathrm{COLI1Al}}$ score and progesterone or androgen receptor status or clinicopathological criteria was observed. Also, no significant association

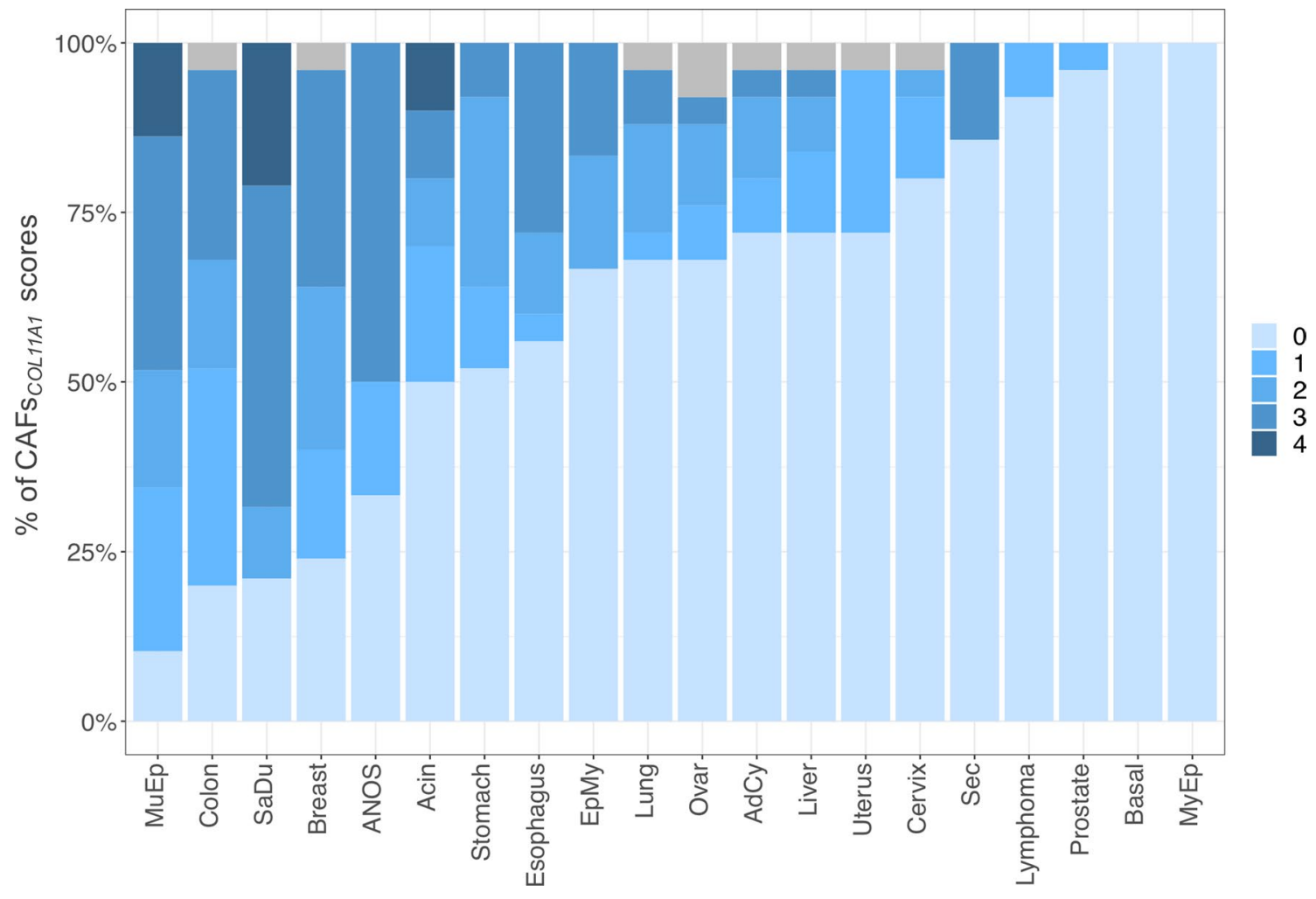

Fig. 1 Relative distribution of stromal $C A F s_{\text {COLIIAl }}$ scores among different tumour types. Stacked bar chart, visualizing the relative distribution of $C A F s_{C O L 11 A 1}$ scores in the analysed tumour types. Both the panCancer and the SGC collective are depicted. $C A F s_{C O L 11 A l}$ scores are color-coded as indicated on the right-hand side. Cases that were not analysable are marked in grey. $M u E p$ mucoepidermoid, $S a D u$ salivary duct, ANOS adenocarcinoma NOS, EpMy epithelial-myoepithelial, $A d C y$ adenoid cystic, Sec secretory, Basal basal cell, MyEp myoepithelial 


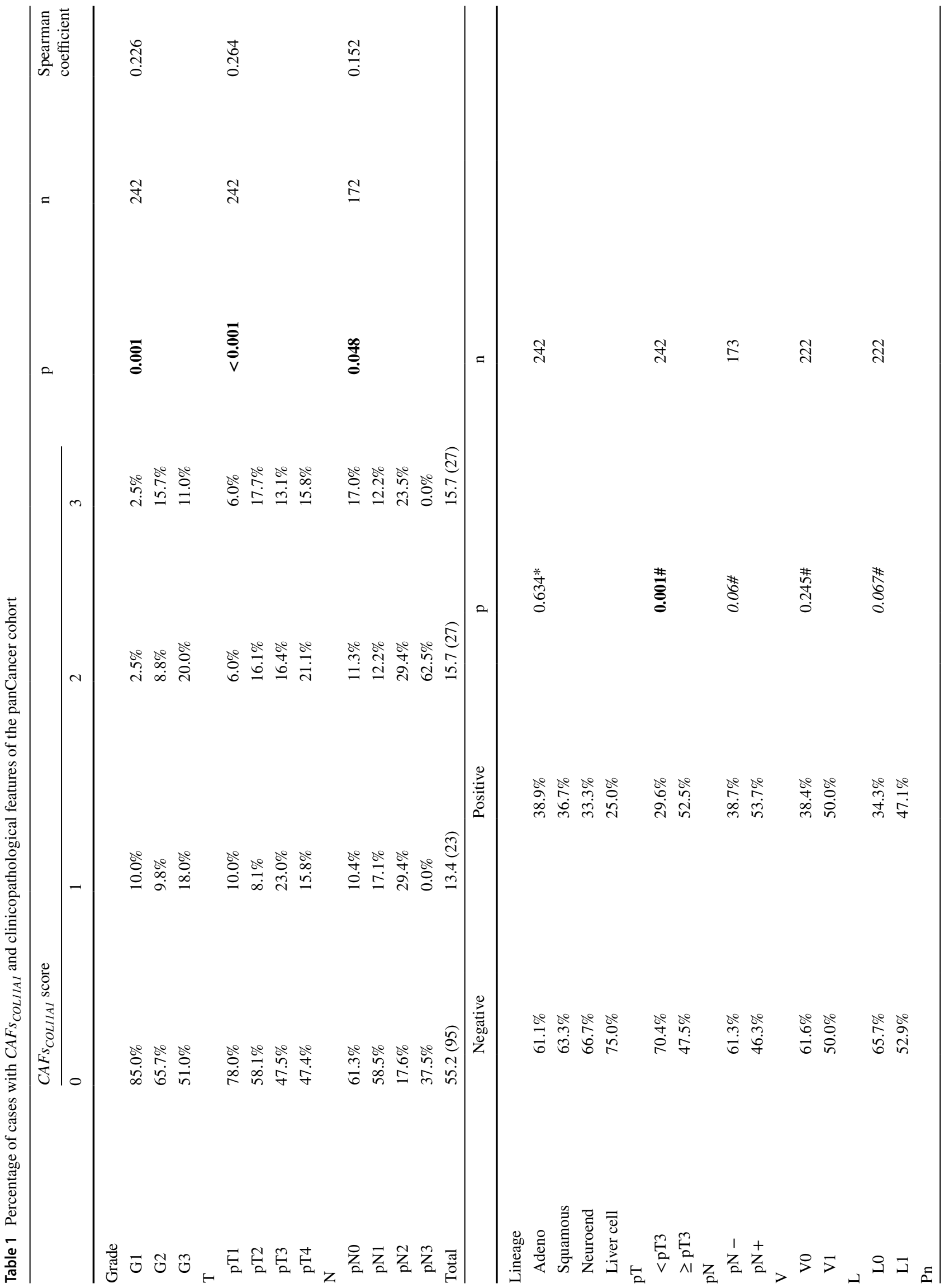




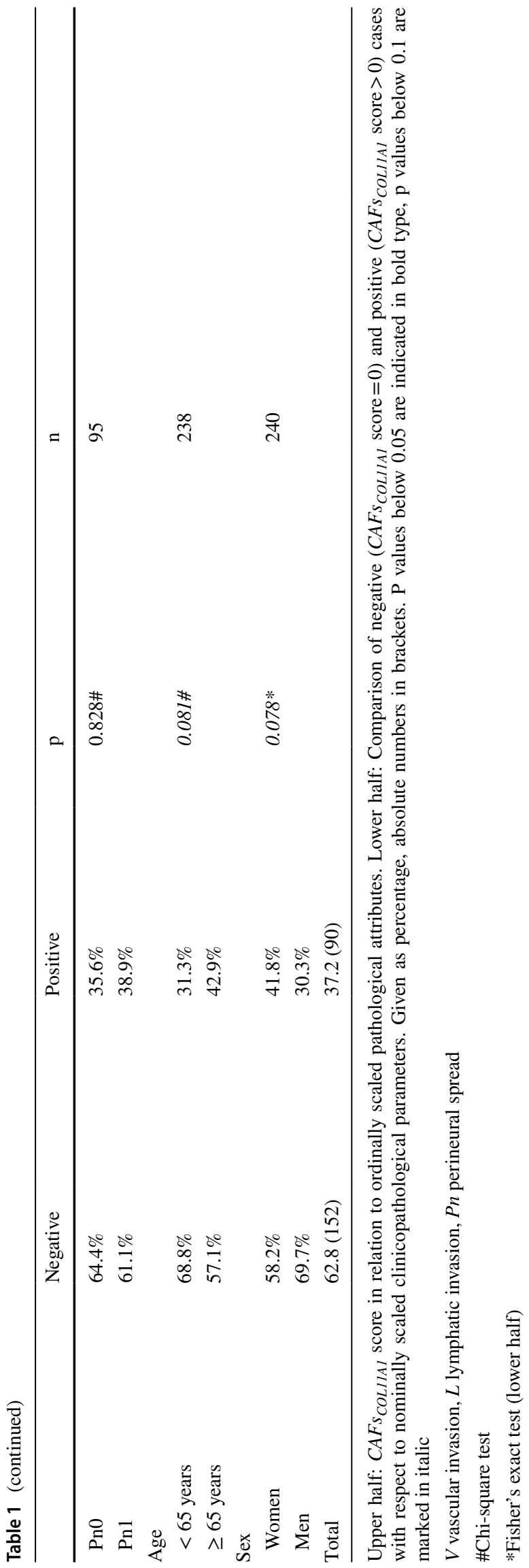

between $\mathrm{CAFs}_{\mathrm{COL11A1}}$ score and clinicopathological parameters, including microsatellite instability was observed for CRC. Of note, tumour cells with staining for COL11A1 $\left(\mathrm{TC}_{\text {COL11A1 }}\right)$ were detected in one $\mathrm{OC}$ as well as one endometrial carcinoma with a percentage of $5 \%$ and $70 \%$ of tumour cells, respectively.

\section{CAF Based COL11A1 Expression Varies Considerably Among SGC Types}

110 SGC were available for COL11A1 mRNA-ISH, containing $29 \mathrm{MuEp}, 25 \mathrm{AdCy}, 19$ salivary duct carcinomas ( $\mathrm{SaDu}$ ), 10 acinic cell carcinomas (Acin), 7 secretory carcinomas (Sec), 6 epithelial-myoepithelial carcinomas (EpMy), 6 adenocarcinomas not otherwise specified (ANOS) as well as 4 basal cell (Bas) and 4 myoepithelial carcinomas (MyEp).

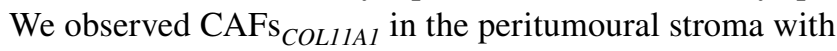
marked differences across the different subtypes (Figs. 1 and 2). While frequencies of more or equal to $50 \%$ of cases

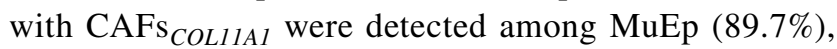
$\mathrm{SaDu}(78.9 \%)$ and Acin (50.0\%), MyEp and Bas showed no CAFs COL11A1 $_{\text {at all. A heterogeneous distribution was }}$ observed in EpMy (33.3\%), AdCy (28.0\%) and Sec (14.3\%). $\mathrm{A} \mathrm{CAFs}_{\text {COL11A1 }}$ score of 4 was only detected among MuEp and $\mathrm{SaDu}$ - none of the tumours from other organs exhibited such intense staining.

When all SGC cases were pooled, CAFs ${ }_{\text {COL11A1 }}$ score positively correlated with higher $\mathrm{N}$-status and CD8 + T cell infiltration ( $p=0.015$ and 0.017 , respectively, Table 2). Interestingly, all cases with vascular invasion by the tumour cells also exhibited CAFs ${ }_{\text {COL11Al }}(\mathrm{p}=0.004)$. Moreover, the presence of $\mathrm{CAFs}_{\text {COL11Al }}$ was associated with perineural spread $(\mathrm{p}=0.004)$. No association between CAFs COL11A1 $_{1}$ and either tumour grade or pT-status was observed in the SGC cohort. On single-entity level, AdCy with CAFs ${ }_{\text {COL11A1 }}$ were more likely to exhibit perineural spread $(\mathrm{p}=0.007)$ or a TP53 mutation ( $\mathrm{p}=0.003$; Table S3). No other significant

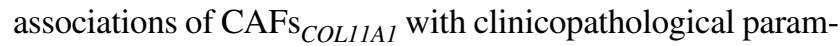
eters were observed in the other tumour types.

For 14 cases, both the primary and a nodal metastasis were analysed (Table S4). In 50\% of the cases, both the primary and the metastasis were either positive or negative for CAFs $_{\text {COL11A1 }} .35 .7 \%$ were positive in the primary but not in the nodal metastasis while in the opposite was the case in $14.3 \%$.

\section{Tumour Cell Based COL11A1 Expression is Restricted to SGC with Intercalated Duct Origin and Varies Markedly Among the Different Histotypes}

In addition to a staining of CAFs, some SGC types also exhibited $\mathrm{TC}_{\text {COL11Al }}$. The highest rate of tumours with $\mathrm{TC}_{\text {COL11Al }}$ was observed among MyEp $(75.0 \%, \mathrm{n}=4)$, AdCy 


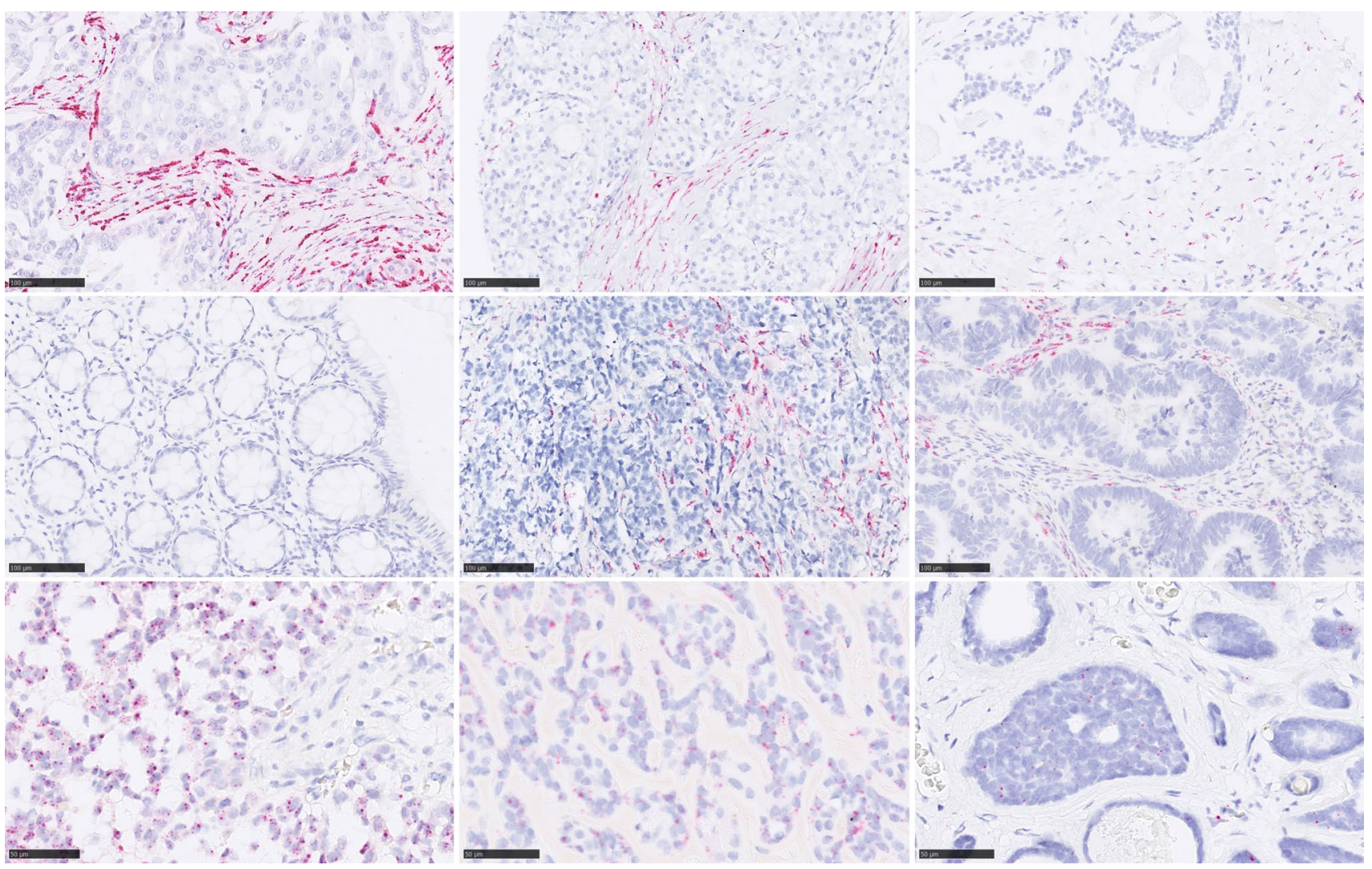

Fig. 2 COL11A1 mRNA expression by CAFs $\left(\mathrm{CAFs}_{\mathrm{COL} 11 \mathrm{~A} 1}\right)$ and tumour cells $\left(\mathrm{TC}_{\mathrm{COL11A1}}\right)$. Top Row: $\mathrm{CAFs}_{\mathrm{COL11A1}}$ in $\mathrm{SaDu}$ (Score 4),

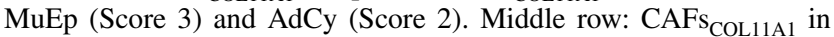

$(52.0 \%, \mathrm{n}=25)$ and EpMy $(50.0 \%, \mathrm{n}=6)$. Similarly, the mean percentage of $\mathrm{TC}_{C O L 11 A 1}$ in individual tumours was highest in MyEp followed by EpMy and AdCy (Table S5). Conversely, these entities showed low frequencies of cases with $\mathrm{CAFs}_{\mathrm{COL11A1}}$ of $0.0 \%, 28.0 \%$ and $33.3 \%$, respectively (Fig. 3A). As expected, $\mathrm{TC}_{\mathrm{COLI1AI}}$ were inversely correlated with the presence of $\mathrm{CAFs}_{\text {COL11AI }}(\mathrm{p}<0.001$, Fig. 3B). This nearly mutually exclusive pattern was sustained by the fact, that only $4 \%$ of all cases were positive for both tumour cell and stromal COL11A1, while 69\% stained exclusively for either of the two patterns (Fig. 3C).

Neither stromal nor intratumoural COL11A1 staining was associated with an alteration of 5-year event-free survival.

\section{While a Parallel Expression of COL11A1 Protein and RNA is Observed in most Tumour Types, in AdCy, Protein Abundance Markedly Exceeds RNA Expression}

Using MSI, COL11A1 protein was measured in TMA tissue samples from both cohorts. After tryptic cleavage, we detected one COL11A1 peptide [(R) GEKGEAGPPGAAGPPGAK(G); m/z value: 1545.82]. normal colon mucosa (Score 0), ER + breast carcinoma (Score 3) and colon carcinoma (Score 2). Bottom row: $\mathrm{TC}_{\mathrm{COL} 11 \mathrm{~A} 1}$ in MyEp (90\%), EpMy (80\%), AdCy (50\%). 400x, reference bar: $50 \mu \mathrm{m}$

Among the different primary sites, the highest intensities were noted for SGC, breast and colon carcinomas, which largely confirmed our results from the RNA-ISH analysis (Fig. 4A). When comparing the different SGC types, the highest intensities for COL11A1 protein were measured in $\mathrm{SaDu}$ and $\mathrm{AdCy}$, resulting in a significant difference to the other histologic groups (p value < 0.001) (Fig. 4B). Even though this finding supports the notion that COL11A1 is markedly upregulated in $\mathrm{SaDu}$, it is remarkable that the moderate frequency of $\mathrm{CAFs}_{\text {COL11Al }}$ and $\mathrm{TC}_{\text {COL11Al }}$ in AdCy results in such pronounced protein expression. This seeming discrepancy between ISH and MSI results might be traced back to a slow turnover of COL11A1 in AdCy, possibly due to a relative absence of CAFs in these tumours.

\section{Discussion}

Recently, we profiled the expression of several ECM genes in SGC and discovered that COL11Al is part of an ECM gene signature which is distinctively upregulated in $\mathrm{SaDu}$ [28]. Here, for the first time we assess the frequency of $\mathrm{CAFs}_{\text {COLI1AI }}$ in a large group of 110 salivary gland 
Table 2 Percentage of cases with $\mathrm{CAFs}_{\mathrm{COL} 11 \mathrm{~A} 1}$ and clinicopathological features of the SGC cohort

\begin{tabular}{|c|c|c|c|c|c|c|c|c|}
\hline & \multicolumn{5}{|c|}{$C A F_{\text {COLlIAI }}$ score } & \multirow[t]{2}{*}{$\mathrm{p}$} & \multirow[t]{2}{*}{$\mathrm{n}$} & \multirow{2}{*}{$\begin{array}{l}\text { Spearman } \\
\text { coefficient }\end{array}$} \\
\hline & 0 & 1 & 2 & 3 & 4 & & & \\
\hline \multicolumn{9}{|l|}{ Grade } \\
\hline G1 & $32.0 \%$ & $16.0 \%$ & $12.0 \%$ & $24.0 \%$ & $16.0 \%$ & 0.754 & 72 & -0.37 \\
\hline G2 & $40.9 \%$ & $0.0 \%$ & $13.6 \%$ & $36.4 \%$ & $9.1 \%$ & & & \\
\hline G3 & $32.0 \%$ & $16.0 \%$ & $16.0 \%$ & $28.0 \%$ & $8.0 \%$ & & & \\
\hline \multicolumn{9}{|l|}{$\mathrm{pT}$} \\
\hline pT1 & $54.2 \%$ & $12.5 \%$ & $12.5 \%$ & $16.7 \%$ & $4.2 \%$ & 0.209 & 104 & 0.125 \\
\hline pT2 & $40.7 \%$ & $22.2 \%$ & $7.4 \%$ & $25.9 \%$ & $3.7 \%$ & & & \\
\hline pT3 & $52.2 \%$ & $0.0 \%$ & $4.3 \%$ & $21.7 \%$ & $21.7 \%$ & & & \\
\hline pT4a & $47.6 \%$ & $4.8 \%$ & $19.0 \%$ & $23.8 \%$ & $4.8 \%$ & & & \\
\hline pT4b & $22.2 \%$ & $22.2 \%$ & $11.1 \%$ & $33.3 \%$ & $11.1 \%$ & & & \\
\hline \multicolumn{9}{|l|}{$\mathrm{N}$} \\
\hline pNO & $52.3 \%$ & $12.3 \%$ & $9.2 \%$ & $20.0 \%$ & $6.2 \%$ & 0.015 & 102 & 0.239 \\
\hline $\mathrm{pN} 1$ & $44.4 \%$ & $22.2 \%$ & $11.1 \%$ & $22.2 \%$ & $0.0 \%$ & & & \\
\hline $\mathrm{pN} 2$ & $28.6 \%$ & $7.1 \%$ & $14.3 \%$ & $32.1 \%$ & $17.9 \%$ & & & \\
\hline \multicolumn{9}{|l|}{ CD8 } \\
\hline 0 & $55.6 \%$ & $11.1 \%$ & $14.8 \%$ & $18.5 \%$ & $0.0 \%$ & 0.017 & 109 & 0.228 \\
\hline 1 & $48.1 \%$ & $13.0 \%$ & $7.4 \%$ & $24.1 \%$ & $7.4 \%$ & & & \\
\hline 2 & $32.1 \%$ & $7.1 \%$ & $14.3 \%$ & $28.6 \%$ & $17.9 \%$ & & & \\
\hline \multirow[t]{2}{*}{ Total } & $45.9(50)$ & $11.0(12)$ & $11.0(12)$ & $23.9(26)$ & $8.3(9)$ & & & \\
\hline & \multicolumn{2}{|l|}{ Negative } & \multicolumn{3}{|l|}{ Positive } & $\mathrm{p}$ & $\mathrm{n}$ & \\
\hline \multicolumn{9}{|l|}{ pT } \\
\hline$<\mathrm{pT} 3$ & \multicolumn{2}{|l|}{$46.2 \%$} & \multicolumn{3}{|l|}{$53.8 \%$} & $1 \#$ & 105 & \\
\hline$\geq \mathrm{pT} 3$ & \multicolumn{2}{|l|}{$45.3 \%$} & \multicolumn{3}{|l|}{$54.7 \%$} & & & \\
\hline \multicolumn{9}{|l|}{$\mathrm{pN}$} \\
\hline $\mathrm{pN}-$ & \multicolumn{2}{|l|}{$51.5 \%$} & \multicolumn{3}{|l|}{$48.5 \%$} & $0.067 \#$ & 103 & \\
\hline $\mathrm{pN}+$ & \multicolumn{2}{|l|}{$32.4 \%$} & $67.6 \%$ & & & & & \\
\hline V & & & & & & & & \\
\hline V0 & $48.8 \%$ & & $51.2 \%$ & & & 0.004* & 91 & \\
\hline V1 & $0.0 \%$ & & $100.0 \%$ & & & & & \\
\hline $\mathrm{L}$ & & & & & & & & \\
\hline L0 & $46.9 \%$ & & $53.1 \%$ & & & $0.334 *$ & 92 & \\
\hline L1 & $27.3 \%$ & & $72.7 \%$ & & & & & \\
\hline $\mathrm{Pn}$ & & & & & & & & \\
\hline Pn0 & $56.1 \%$ & & $43.9 \%$ & & & 0.004\# & 96 & \\
\hline Pn1 & $23.3 \%$ & & $76.7 \%$ & & & & & \\
\hline Age & & & & & & & & \\
\hline$<65 y$ & $51.4 \%$ & & $48.6 \%$ & & & $0.102 \#$ & 110 & \\
\hline$\geq 65 y$ & $33.3 \%$ & & $66.7 \%$ & & & & & \\
\hline Sex & & & & & & & & \\
\hline Women & $45.9 \%$ & & $54.1 \%$ & & & $1 \#$ & 110 & \\
\hline Men & $44.9 \%$ & & $55.1 \%$ & & & & & \\
\hline TP53 & & & & & & & & \\
\hline Wildtype & $51.4 \%$ & & $48.6 \%$ & & & $0.088 \#$ & 106 & \\
\hline Mutated & $31.3 \%$ & & $68.8 \%$ & & & & & \\
\hline CD8 & & & & & & & & \\
\hline Not inflamed & $50.0 \%$ & & $50.0 \%$ & & & $0.126 \#$ & 110 & \\
\hline Inflamed & $32.1 \%$ & & $67.9 \%$ & & & & & \\
\hline Total & $45.5(50)$ & & $54.5(60)$ & & & & & \\
\hline
\end{tabular}

Upper half: $\mathrm{CAFs}_{\mathrm{COLI1Al}}$ score in relation to ordinally scaled pathological attributes. Comparison of negative $\left(\mathrm{CAFs}_{\mathrm{COL11Al}} \mathrm{score}=0\right)$ and positive $\left(\mathrm{CAFs}_{\mathrm{COLllAl}}\right.$ score $\left.>0\right)$ cases with respect to nominally scaled clinicopathological parameters, given as percentage, absolute numbers in brackets. $P$ values below 0.05 are indicated in bold type, $p$ values below 0.1 are marked in italic 
Table 2 (continued)

$V$ vascular invasion, $L$ lymphatic invasion, $P n$ perineural spread

\#Chi-square test

*Fisher's exact test (lower half)

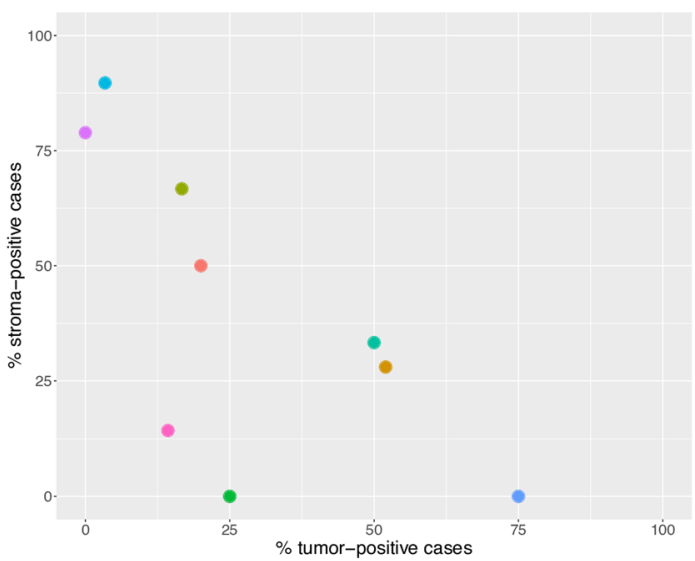

B

\begin{tabular}{|c|c|c|c|}
\hline \multirow{2}{*}{\multicolumn{2}{|c|}{$p<0.001$}} & \multicolumn{2}{|c|}{ Stroma } \\
\hline & & negative & positive \\
\hline \multirow{2}{*}{ Tumor cells } & negative & $34.1 \%(29)$ & $65.9 \%(56)$ \\
\hline & positive & $84.0 \%(21)$ & $16.0 \%$ (4) \\
\hline
\end{tabular}

Fig. 3 Comparison of SGC positive for $\mathrm{CAFs}_{\mathrm{COL11A1}}$ and $\mathrm{TC}_{\mathrm{COL11A} 1}$ in SGC. A Dotplot, locating each carcinoma entity in a bidimensional manner according to the respective percentage of cases with $\mathrm{TC}_{\mathrm{COL11A1}}$ (x axis) and $\mathrm{CAFs}_{\mathrm{COL11A1}}$ (y axis). B Table demonstrating

carcinomas and another cohort which comprises the ten most frequent carcinoma types, lymphomas, and corresponding normal tissue. While an overexpression of COL11A1 has been described for several primaries using bulk expression data, a systematic evaluation of CAFs $\mathrm{COLIIAl}_{1}$ with RNA-ISH has not yet been performed in any tumour type.

Within the panCancer cohort, the highest frequencies of $\mathrm{CAFs}_{\text {COL11Al }}$ and the highest amount of COL11A1 protein was detected in CRC and MC, while COL1 1A1 RNA expression in normal tissue was largely absent. Several studies have revealed that a stromal expression of COL11Al is implicated in the malignant transition in these cancer types [10, 17, 32]. We show for the first time that this overexpression of COL11A1 in MC can be exclusively attributed to COL11A1 production by $\mathrm{CAFs}_{\text {COLIIAl }}$ in the peritumoural stroma. Concordantly, we obtained very similar results for all other carcinomas from various sites in the panCancer cohort. In fact, only one endometrial and one OC displayed tumour cell based COL11A1 production.

We found that the presence of $\mathrm{CAFs}_{C O L 11 A l}$ in the peritumoural stroma correlated with higher tumour grade, $\mathrm{T}$ and $\mathrm{N}$ classification in the panCancer cohort. Although follow

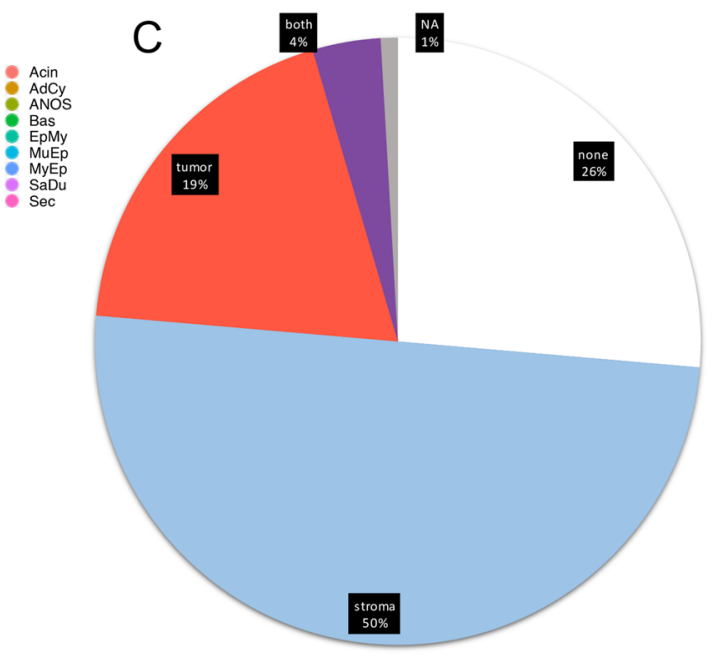

an anti-proportional pattern of COL11A1 expression in the abovementioned tumour compartments. C Pie chart, illustrating the percentage of cases with CAFs $\mathrm{COL11A1}_{1}, \mathrm{TC}_{\mathrm{COL} 11 \mathrm{~A} 1}$ or combined staining

up data was not available, these results are in line with previous studies reporting a correlation between bulk COL11A1 expression and an adverse outcome for many carcinomas [9, 11, 15, 33]. In accordance with Halsted et al. [32], we found that stromal COL11A1 expression correlated with higher grade and ER negativity in MC. These, as well as a high ki67 index which also correlated with $\mathrm{CAFs}_{\text {COL11Al }}$ are all recognised predictors of poor outcome $[34,35]$. In summary, our findings are in line with Toss et al. [10] who revealed that COL11A1 protein expression is associated with adverse prognosis in MC.

While the expression of COL11A1 by CAFs has widely been accepted, it remains controversial whether carcinoma cells also produce COL11A1. Some authors have reported COL11A1 protein expression by tumours cells by analysing carcinoma cell lines [12, 20, 23] or cancer tissues with IHC $[10,23]$. Surprisingly, only few studies have interrogated the mRNA expression in situ by RNA-ISH. Cheon et al. have used both IHC and RNA-ISH on serial sections in OC and found that COL11A1 was nearly exclusively expressed by CAFs. Having compared both methods directly, they reported a higher cellular resolution for RNA-ISH [36]. 
A
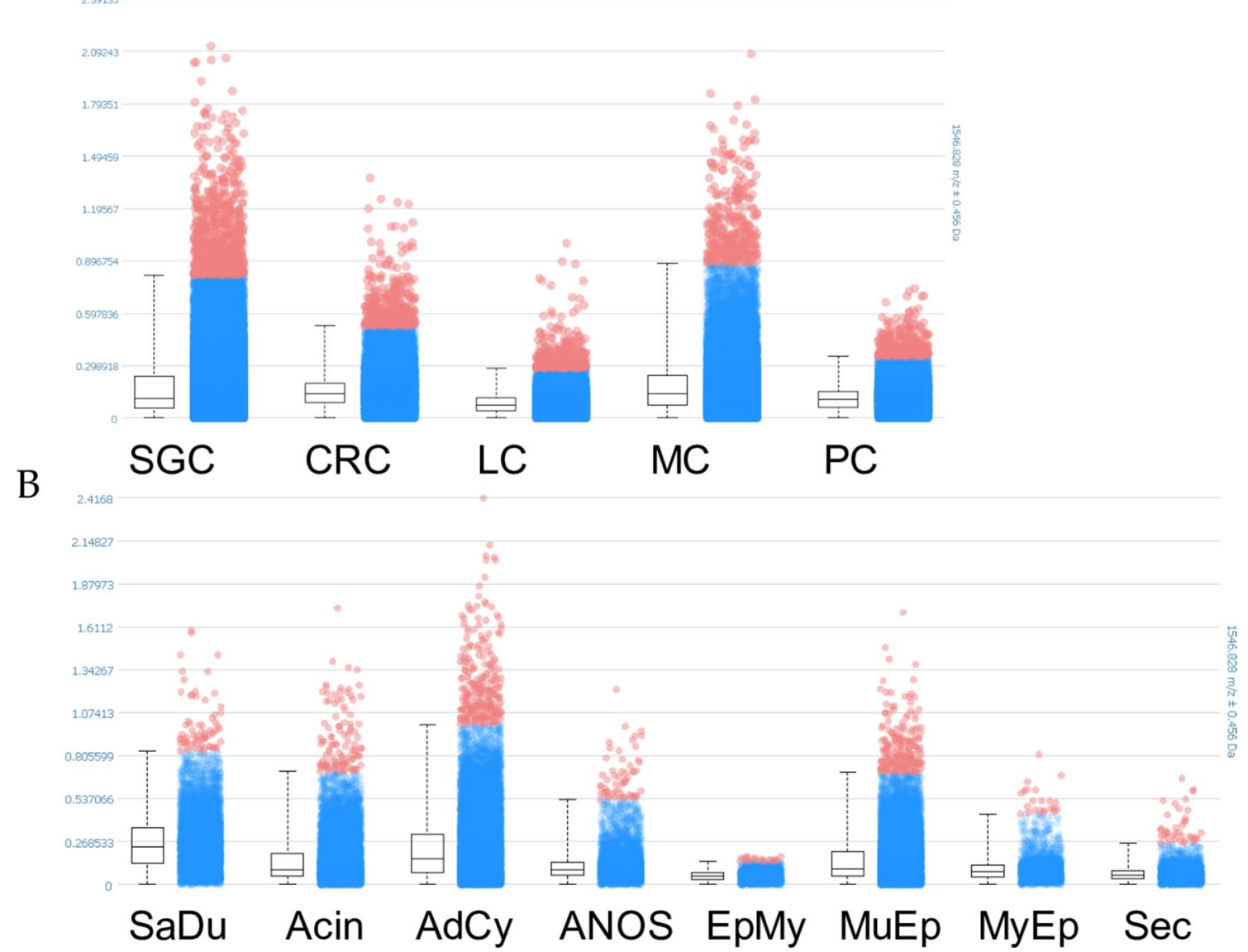

Fig. 4 Distribution of one COL11A1 peptide in TMA sections. Intensity box plots comparing the intensities of the shown $\mathrm{m} / \mathrm{z}$ value for different primary sites (A) and SGC types (B). The horizontal line of the box part represents the mean intensity of the $\mathrm{m} / \mathrm{z}$ value measured over all pixels. The blue dots represent pixel with spectra in which intensities of the $\mathrm{m} / \mathrm{z}$ value are between the lower and upper quantile. The red dots represent pixel with spectra outside of these intervals.

Other authors have reported similar results for OC [9] and gastric carcinoma [37]. In line with these findings, we only detected $\mathrm{TC}_{\text {COLIIAI }}$ in one OC and one endometrial carcinoma. This data indicates that tumour cell based COL11A1 expression among the most prevalent carcinoma types is at least minor if not negligible. In our opinion, RNA-ISH assays rather than IHC should be used to validate the cellular origin of ECM proteins in tumour tissue and cell lines.

The so-called desmoplastic stroma is characterised by an increased stiffness due to deposition and crosslinking of collagens $[38,39]$. These altered mechanic properties result in protumourigenic signalling through integrin-mediated mechanotransduction and a reduction of tissue perfusion with decreased bioavailability of antineoplastic agents [40, 41]. Jia et al. discovered that COL11A1 is a central component of a stromal pan-cancer gene signature. FAP, another
$S G C$ salivary gland carcinoma, $C R C$ colorectal carcinoma, $L C$ lung carcinoma, $M C$ mamma carcinoma, $P C$ prostate carcinoma, $S a D u$ salivary duct carcinoma, Acin acinic cell carcinoma, ANOS adenocarcinoma not-otherwise-specific, EpMy epithelial-myoepithelial carcinoma, $M u E p$ mucoepidermoid carcinoma, $M y E p$ myoepithelial carcinoma, Sec secretory carcinoma

CAFs marker, fibronectin and four collagens were among the ten genes most highly correlated with COL11A1 [9]. Thus, the expression of COL11A1 might additionally predict the presence of other collagens, which are major contributors to the ECM. Since the desmoplastic stroma is investigated as therapeutic target, diagnostic tests to quantify the amount of ECM deposition might be warranted in the future. Regarding the strong correlation of COL11A1 expression with other ECM components, COL11A1-ISH might be a predictor for future anti-desmoplastic therapies.

Moreover, several studies have recently revealed that COL11A1 mediated processes might be a promising therapeutic target by themselves. COL11A1 is upregulated in chemoresistant carcinomas [12, 42] including OC [36] and has subsequently been suspected to be functionally involved in the process. Rada et al. mechanistically demonstrated that 
COL11A1 inhibits tumour cell apoptosis by activation of the Src-PI3K/Akt-NF-kB pathway [11]. Nallantighal et al. found out that COL11A1 upregulates fatty acid oxidase (FAO) which confers cisplatin resistance [22]. The fact that FAO inhibitors, which have been approved for the therapy of cardiac disease [43, 44], also display an antineoplastic effect in-vitro and in-vivo makes them interesting candidates for anticancer therapy [45-47]. Thus, COL11A1 might be a feasible biomarker for a FAO-inhibitor therapy.

The frequency of $\mathrm{CAFs}_{\mathrm{COLI1AI}}$ varied dramatically among the different SGC subtypes. SaDu displayed the highest frequencies of scores 3 and 4 , the latter being a staining intensity that has not been observed in any of the tumours from the panCancer cohort. Since SaDu have many overlapping features with ductal MC, it is not surprising that $\mathrm{SaDu}$ and $\mathrm{MC}$ are both characterised by high frequencies of $\mathrm{CAFs}_{C O L 11 A I}$ and an absence of $\mathrm{TC}_{\text {COLIIAI }}$. Together, our results provide a strong rationale to further investigate the potential of anti-desmoplastic therapies in $\mathrm{SaDu}$ and MC.

Interestingly, we found that the rate of CAFs $\mathrm{COLIIAl}_{\text {I }}$ positive AdCy cases was significantly higher among TP53 mutated tumours. The fact that p53 mutation is an adverse prognosticator for AdCy [48] further supports our notion that $\mathrm{CAFs}_{\mathrm{COL11Al}}$ are associated to surrogates of poor outcome. As some CAF subtypes have been attributed immunomodulatory properties, we also scored the number of CD8 + T-lymphocytes but did not find a correlation with

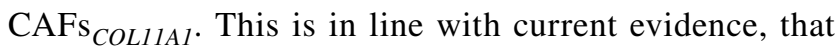
immunomodulatory functions are exerted by specialised iCAFs rather than by mCAFs which are instead involved in ECM production $[49,50]$.

Ohtomo et al. found that SGC which derive from the acini (Acin, Sec) and the intercalated duct (AdCy, MyEp, Bas, EpMy) express the neural crest transcription factor SOX10, while tumours emerging from the excretory duct ( $\mathrm{SaDu}, \mathrm{MuEp}$ ) do not [51]. Strikingly, we discovered that while COL11A1 expression in the latter is nearly restricted to CAFs $\mathrm{COLI1Al}_{\text {in }}$ in their vicinity, SOX10 + tumours produce $C O L 11 A 1$ in the tumour cells at varying rates. Interestingly, the mode of COL11Al production was nearly mutually exclusive as only $4 \%$ of the tumours exhibited both CAFs COL11AI $_{\text {and }} \mathrm{TC}_{\text {COL11AI. This suggests that }}$ tumours with $\mathrm{TC}_{\text {COL11AI }}$ "do not require" $\mathrm{CAFs}_{\text {COL1IAI }}$ in their TME. Together with the fact that $73 \%$ of all SGC produced COL11A1 in either way, it indicates that COL11A1 might play a major role in SGC tumourigenesis. Interestingly, we revealed that while the RNA expression of COL11A1 in AdCy was not particularly high, the protein deposition in the tumours was marked. We speculate, that this seeming discrepancy might be traced back to a slow turnover of COL11A1 in AdCy, possibly due to a relative absence of CAFs in these tumours. As outlined above,
COL11A1 production strongly correlates with expression of several other ECM molecules. Thus, we hypothesise that SOX10 + SGC cells might produce most of their ECM themselves. Even though COL11A1 production by tumour cells has been reported for mesenchymal neoplasms [20], we are the first to report this mechanism in carcinomas. These fundamental differences in the mode of COL11A1 production might have implications on the effectiveness of COL11A1- and FAO-targeting drugs and might thus impact clinical decision making in the future.

The descriptive character of this study does not allow for mechanistic conclusions concerning the function of COL11A1. Moreover, as the size of each individual tumour group was rather small, correlations with clinicopathological parameters must be interpreted with caution and should be further validated in larger, individual studies.

We systematically assessed the frequency of $\mathrm{CAFs}_{\text {COLIIAI }}$ and $\mathrm{TC}_{\text {COLIIAI }}$ in the most prevalent carcinoma types and SGC. We report that (1) MC, CRC and SaDu do not produce COL11Al themselves but are highly infiltrated by $\mathrm{CAFs}_{\mathrm{COLI1Al}}$ and might thus be promising candidates for antidesmoplastic or COL11A1-targeted therapies. (2) COL11Al is produced by $\mathrm{CAFs}_{\mathrm{COLI1Al}}$ and intercalated duct SGC cells in a mutually exclusive manner which represents a novel mode of ECM production in carcinomas. (3) Finally, we propose a 4-tiered RNAISH-based scoring system for CAFs $\mathrm{COLI1AI}_{\text {which could }}$ be highly relevant for future ECM or COL11A1-targeted therapies.

Supplementary Information The online version contains supplementary material available at https://doi.org/10.1007/s12105-021-01370-0.

Acknowledgements We acknowledge Wiebke Jeske and Magdalene Fielenbach for their excellent technical support.

Author Contributions Conceptualisation, AQ and CA; methodology, $\mathrm{CA}, \mathrm{AQ}, \mathrm{FH}$ and FvE; software, $\mathrm{CA}$ and $\mathrm{FH}$; validation, $\mathrm{CA}, \mathrm{FH}$ and $\mathrm{AQ}$; formal analysis, $\mathrm{CA}$ and $\mathrm{FH}$; investigation, $\mathrm{CA}, \mathrm{AQ}$ and $\mathrm{FH}$; resources, JPK, FvE, OGL and RB; data curation, JPK, LN and PW; writing - original draft preparation, $\mathrm{CA}$; writing - review and editing, JPK, AQ, FH, OG-L, FvE, PW, LN and RB; visualisation, CA and FH; supervision, AQ and JPK; project administration, JPK and AQ; funding acquisition, not applicable. All authors have read and agreed to the published version of the manuscript. All authors contributed substantially to the conception of this study and the writing of the manuscript. This material has not been published and is not under consideration elsewhere.

Funding Open Access funding enabled and organized by Projekt DEAL. CA currently receives financial support from the Else KrönerFresenius Foundation.

Data Availability All primary data of the semiquantitative RNA-ISH analysis are available on request. 
Code Availability The R code used for statistical analysis is available on request.

\section{Declarations}

Conflict of interest The authors declare that they have no conflict of interest.

Ethical Approval All procedures performed involving human participants were in accordance with the ethical standards of the institutional research committee and with the 1964 Helsinki declaration and its later amendments or comparable ethical standards.

Informed Consent Informed consent was obtained from all individual participants included in the study.

Open Access This article is licensed under a Creative Commons Attribution 4.0 International License, which permits use, sharing, adaptation, distribution and reproduction in any medium or format, as long as you give appropriate credit to the original author(s) and the source, provide a link to the Creative Commons licence, and indicate if changes were made. The images or other third party material in this article are included in the article's Creative Commons licence, unless indicated otherwise in a credit line to the material. If material is not included in the article's Creative Commons licence and your intended use is not permitted by statutory regulation or exceeds the permitted use, you will need to obtain permission directly from the copyright holder. To view a copy of this licence, visit http://creativecommons.org/licenses/by/4.0/.

\section{References}

1. Priya SK, Nagare RP, Sneha VS, Sidhanth C, Bindhya S, Manasa $\mathrm{P}$, et al. Tumour angiogenesis-origin of blood vessels. Int J Cancer. 2016;139:729-35.

2. Hernández de la Cruz ON, López-González JS, García-Vázquez R, Salinas-Vera YM, Muñiz-Lino MA, Aguilar-Cazares D, et al. Regulation networks driving vasculogenic mimicry in solid tumors. Front Oncol. 2020;9:1419.

3. Samadi AK, Georgakilas AG, Amedei A, Amin A, Bishayee A, Lokeshwar BL, et al. A multi-targeted approach to suppress tumor-promoting inflammation. Semin Cancer Biol. 2015;35(Suppl):S151-84.

4. Gerarduzzi C, Hartmann U, Leask A, Drobetsky E. The matrix revolution: matricellular proteins and restructuring of the cancer microenvironment. Cancer Res. 2020;80:2705.

5. Wu J, Liang C, Chen M, Su W. Association between tumor-stroma ratio and prognosis in solid tumor patients: a systematic review and meta-analysis. Oncotarget. 2016;7:68954-65.

6. Kalluri R. The biology and function of fibroblasts in cancer. Nat Rev Cancer. 2016;16:582-98.

7. Rafaeva M, Erler JT. Framing cancer progression: influence of the organ- and tumour-specific matrisome. FEBS J. 2020;287:1454-77.

8. Abyaneh HS, Regenold M, McKee TD, Allen C, Gauthier MA. Towards extracellular matrix normalization for improved treatment of solid tumors. Theranostics. 2020;10:1960-80.

9. Jia D, Liu Z, Deng N, Tan TZ, Huang RY-J, Taylor-Harding B, et al. A COL11A1-correlated pan-cancer gene signature of activated fibroblasts for the prioritization of therapeutic targets. Cancer Lett. 2016;382:203-14.
10. Toss MS, Miligy IM, Gorringe KL, Aleskandarany MA, Alkawaz A, Mittal K, et al. Collagen (XI) alpha- 1 chain is an independent prognostic factor in breast ductal carcinoma in situ. Modern Pathol. 2019;32:1460-72.

11. Rada M, Nallanthighal S, Cha J, Ryan K, Sage J, Eldred C, et al. Inhibitor of apoptosis proteins (IAPs) mediate collagen type XI alpha 1-driven cisplatin resistance in ovarian cancer. Oncogene. 2018;37:4809-20.

12. Shen L, Yang M, Lin Q, Zhang Z, Zhu B, Miao C. COL11A1 is overexpressed in recurrent non-small cell lung cancer and promotes cell proliferation, migration, invasion and drug resistance. Oncol Rep. 2016;36:877-85.

13. Ewald JA, Downs TM, Cetnar JP, Ricke WA. Expression microarray meta-analysis identifies genes associated with Ras/MAPK and related pathways in progression of muscle-invasive bladder transition cell carcinoma. PLoS ONE. 2013;8:e55414.

14. Boguslawska J, Kedzierska H, Poplawski P, Rybicka B, Tanski Z, Piekielko-Witkowska A. Expression of genes involved in cellular adhesion and extracellular matrix remodeling correlates with poor survival of patients with renal cancer. J Urol. 2016;195:1892-902.

15. Large TYSL, Mantini G, Meijer LL, Pham TV, Funel N, van Grieken NCT, et al. Microdissected pancreatic cancer proteomes reveal tumor heterogeneity and therapeutic targets. JCI Insight. 2020;5:e138290.

16. García-Pravia C, Galván JA, Gutiérrez-Corral N, Solar-García L, García-Pérez E, García-Ocaña M, et al. Overexpression of COL11A1 by cancer-associated fibroblasts: clinical relevance of a stromal marker in pancreatic cancer. PLoS ONE. 2013;8:e78327.

17. Fischer H, Stenling R, Rubio C, Lindblom A. Colorectal carcinogenesis is associated with stromal expression of COL11A1 and COL5A2. Carcinogenesis. 2001;22:875-8.

18. Fischer H, Salahshor S, Stenling R, Björk J, Lindmark G, Iselius $\mathrm{L}$, et al. COL11A1 in FAP polyps and in sporadic colorectal tumors. BMC Cancer. 2001;1:17.

19. Yoshioka H, Iyama K, Inoguchi K, Khaleduzzaman M, Ninomiya Y, Ramirez F. Developmental pattern of expression of the mouse alpha 1 (XI) collagen gene (Col11a1). Dev Dyn. 1995;204:41-7.

20. Vázquez-Villa F, García-Ocaña M, Galván JA, García-Martínez J, García-Pravia C, Menéndez-Rodríguez P, et al. COL11A1/(pro) collagen 11A1 expression is a remarkable biomarker of human invasive carcinoma-associated stromal cells and carcinoma progression. Tumour Biol. 2015;36:2213-22.

21. Fiori ME, Di Franco S, Villanova L, Bianca P, Stassi G, De Maria R. Cancer-associated fibroblasts as abettors of tumor progression at the crossroads of EMT and therapy resistance. Mol Cancer. 2019;18:70.

22. Nallanthighal S, Rada M, Heiserman JP, Cha J, Sage J, Zhou B, et al. Inhibition of collagen XI alpha 1-induced fatty acid oxidation triggers apoptotic cell death in cisplatin-resistant ovarian cancer. Cell Death Dis. 2020;11:1.

23. Wu Y-H, Chang T-H, Huang Y-F, Chen C-C, Chou C-Y. COL11A1 confers chemoresistance on ovarian cancer cells through the activation of Akt/c/EBP $\beta$ pathway and PDK1 stabilization. Oncotarget. 2015;6:23748-63.

24. Skálová A, Vanecek T, Sima R, Laco J, Weinreb I, Perez-Ordonez $\mathrm{B}$, et al. Mammary analogue secretory carcinoma of salivary glands, containing the ETV6-NTRK3 fusion gene: a hitherto undescribed salivary gland tumor entity. Am J Surg Pathol. 2010;34:599-608.

25. Arolt C, Meyer M, Ruesseler V, Nachtsheim L, Wuerdemann N, Dreyer T, et al. Lymphocyte activation gene 3 (LAG3) protein expression on tumor-infiltrating lymphocytes in aggressive and TP53-mutated salivary gland carcinomas. Cancer Immunol Immunother. 2020;69:1363-73.

26. Kesar N, Winkelmann R, Oppermann J, Ghanaati S, Martin D, Neumayer T, et al. Prognostic impact of CD8-positive 
tumour-infiltrating lymphocytes and PD-L1 expression in salivary gland cancer. Oral Oncol. 2020;111:104931.

27. Xu B, Jungbluth AA, Frosina D, Alzumaili B, Aleynick N, Slodkowska $\mathrm{E}$, et al. The immune microenvironment and expression of PD-L1, PD-1, PRAME and MHC I in salivary duct carcinoma. Histopathology. 2019;75:672-82.

28. Arolt C, Meyer M, Hoffmann F, Wagener-Ryczek S, Schwarz D, Nachtsheim L, et al. Expression profiling of extracellular matrix genes reveals global and entity-specific characteristics in adenoid cystic, mucoepidermoid and salivary duct carcinomas. Cancers (Basel). 2020;12:2466.

29. Cancer Statistics [Internet]. SEER. [cited 2020 Oct 17]. Available from: https://seer.cancer.gov/statistics/index.html

30. Wang F, Flanagan J, Su N, Wang L-C, Bui S, Nielson A, et al. RNAscope. J Mol Diagn. 2012;14:22-9.

31. Create Elegant Data Visualisations Using the Grammar of Graphics [Internet]. [cited 2020 Oct 18]. Available from: https://ggplo t2.tidyverse.org/

32. Halsted KC, Bowen KB, Bond L, Luman SE, Jorcyk CL, Fyffe WE, et al. Collagen $\alpha 1(\mathrm{XI})$ in normal and malignant breast tissue. Modern Pathol. 2008;21:1246-54.

33. Pearce OMT, Delaine-Smith R, Maniati E, Nichols S, Wang J, Böhm S, et al. Deconstruction of a metastatic tumor microenvironment reveals a common matrix response in human cancers. Cancer Discov. 2018;8:304-19.

34. Knight WA, Livingston RB, Gregory EJ, McGuire WL. Estrogen receptor as an independent prognostic factor for early recurrence in breast cancer. Cancer Res. 1977;37:4669-71.

35. Yerushalmi R, Woods R, Ravdin PM, Hayes MM, Gelmon KA. Ki67 in breast cancer: prognostic and predictive potential. Lancet Oncol. 2010;11:174-83.

36. Cheon D-J, Tong Y, Sim M-S, Dering J, Berel D, Cui X, et al. A collagen-remodeling gene signature regulated by TGF- $\beta$ signaling is associated with metastasis and poor survival in serous ovarian cancer. Clin Cancer Res. 2014;20:711-23

37. Zhao Y, Zhou T, Li A, Yao H, He F, Wang L, et al. A potential role of collagens expression in distinguishing between premalignant and malignant lesions in stomach. Anat Rec (Hoboken). 2009;292:692-700.

38. Cox TR, Bird D, Baker A-M, Barker HE, Ho MW-Y, Lang G, et al. LOX-mediated collagen crosslinking is responsible for fibrosisenhanced metastasis. Cancer Res. 2013;73:1721-32.

39. Senthebane DA, Rowe A, Thomford NE, Shipanga H, Munro D, Al Mazeedi MAM, et al. The role of tumor microenvironment in chemoresistance: to survive, keep your enemies closer. Int J Mol Sci. 2017;18:1586.

40. Kechagia JZ, Ivaska J, Roca-Cusachs P. Integrins as biomechanical sensors of the microenvironment. Nat Rev Mol Cell Biol. 2019;20:457-73.
41. Murphy JE, Wo JY, Ryan DP, Clark JW, Jiang W, Yeap BY, et al. Total neoadjuvant therapy with FOLFIRINOX in combination with losartan followed by chemoradiotherapy for locally advanced pancreatic cancer: a phase 2 clinical trial. JAMA Oncol. 2019;5:1020-7.

42. Farmer P, Bonnefoi H, Anderle P, Cameron D, Wirapati P, Wirapati $\mathrm{P}$, et al. A stroma-related gene signature predicts resistance to neoadjuvant chemotherapy in breast cancer. Nat Med. 2009;15:68-74.

43. Nash DT, Nash SD. Ranolazine for chronic stable angina. Lancet. 2008;372:1335-41.

44. Lee L, Campbell R, Scheuermann-Freestone M, Taylor R, Gunaruwan $\mathrm{P}$, Williams L, et al. Metabolic modulation with perhexiline in chronic heart failure: a randomized, controlled trial of shortterm use of a novel treatment. Circulation. 2005;112:3280-8.

45. Sawyer BT, Qamar L, Yamamoto TM, McMellen A, Watson ZL, Richer JK, et al. Targeting fatty acid oxidation to promote anoikis and inhibit ovarian cancer progression. Mol Cancer Res. 2020;18:1088-98.

46. Schlaepfer IR, Rider L, Rodrigues LU, Gijón MA, Pac CT, Romero L, et al. Lipid catabolism via CPT1 as a therapeutic target for prostate cancer. Mol Cancer Ther. 2014;13:2361-71.

47. Wang Y-N, Zeng Z-L, Lu J, Wang Y, Liu Z-X, He M-M, et al. CPT1A-mediated fatty acid oxidation promotes colorectal cancer cell metastasis by inhibiting anoikis. Oncogene. 2018;37:6025-40.

48. Li Q, Huang P, Zheng C, Wang J, Ge M. Prognostic significance of p53 immunohistochemical expression in adenoid cystic carcinoma of the salivary glands: a meta-analysis. Oncotarget. 2017;8:29458-73.

49. Chen Z, Zhou L, Liu L, Hou Y, Xiong M, Yang Y, et al. Singlecell RNA sequencing highlights the role of inflammatory cancerassociated fibroblasts in bladder urothelial carcinoma. Nat Commun. 2020;11:5077.

50. Öhlund D, Handly-Santana A, Biffi G, Elyada E, Almeida AS, Ponz-Sarvise M, et al. Distinct populations of inflammatory fibroblasts and myofibroblasts in pancreatic cancer. J Exp Med. 2017;214:579-96.

51. Ohtomo R, Mori T, Shibata S, Tsuta K, Maeshima AM, Akazawa $\mathrm{C}$, et al. SOX10 is a novel marker of acinus and intercalated duct differentiation in salivary gland tumors: a clue to the histogenesis for tumor diagnosis. Modern Pathol. 2013;26:1041-50.

Publisher's Note Springer Nature remains neutral with regard to jurisdictional claims in published maps and institutional affiliations. 